\title{
ERRATUM
}

\section{Bacterial Model System for Screening and Determining Optimal Concentration of Anti-caries Natural Extracts}

\author{
Min Jung Kim ${ }^{1,2 \dagger}$, Chun Sung Kim ${ }^{1,2 \dagger}$, Jae-Yoon Park ${ }^{3 \dagger}$, Soon-Nang Park ${ }^{1,2}$, So Young Yoo ${ }^{1}$, \\ Sook-Young Lee ${ }^{4}$, and Joong-Ki Kook ${ }^{1,2 *}$
}

${ }^{1}$ Department of Oral Biochemistry, ${ }^{2}$ Department of Dental Materials, School of Dentistry, Chosun University, Gwangju 501-759, Republic of Korea ${ }^{1}$ Department of Oral Biochemistry and ${ }^{2}$ Oral Biology Research Institute, School of Dentistry, Chosun University, Gwangju 501-759, Republic of Korea ${ }^{3}$ Department of Biochemistry and Molecular Biology, Medical School, Chosun University, Gwangju 501-759, Republic of Korea ${ }^{4}$ MRC Center, School of Dentistry, Chosun University, Gwangju 501-759, Republic of Korea

(Received January 11, 2011 / Accepted January 26, 2011)

In the article by Kim et al. that appears in the Journal of Microbiology $2011 ; 49,165-168$. In $17^{\text {th }}$ line of right colume in page 167, KCOM 1228 should be changed as KCOM 1128. 